\title{
Towards a future without stocking: harvest and river regulation determine long-term population viability of migratory salmonids
}

\author{
Chloé R. Nater ${ }^{1,2, *}$, Marlene W. Stubberud ${ }^{1}$, Øystein Langangen ${ }^{3}$, Atle Rustadbakken ${ }^{4}$, \\ S. Jannicke Moe ${ }^{5}$, Torbjørn Ergon ${ }^{1}$, L. Asbjørn Vøllestad ${ }^{1}$, Yngvild Vindenes ${ }^{1}$ \\ ${ }^{1}$ Centre for Ecological and Evolutionary Synthesis (CEES), Department of Biosciences, University of Oslo, 0316 Oslo, Norway \\ ${ }^{2}$ Centre for Biodiversity Dynamics (CBD), Norwegian University of Science and Technology, 7491 Trondheim, Norway \\ ${ }^{3}$ Section for Aquatic Biology and Toxicology (AQUA), Department of Biosciences, University of Oslo, 0316 Oslo, Norway \\ ${ }^{4}$ Norconsult AS, 2317 Hamar, Norway \\ ${ }^{5}$ Norwegian Institute for Water Research (NIVA), 0349 Oslo, Norway
}

\begin{abstract}
Freshwater species are particularly vulnerable to emerging threats linked to climate change because they are often already heavily impacted by habitat destruction, pollution, and exploitation. For many harvested populations of freshwater fish, these combined impacts have been mitigated for decades through stocking with captive-bred individuals. However, stocking may lead to loss of genetic variation, which may be crucial for adaptation under climate change. Exploration of sustainable alternatives is therefore paramount. We used a female-based integral projection model (IPM) to assess the consequences of terminating a long-term stocking programme for a population of landlocked, migratory brown trout Salmo trutta, and to evaluate relative effectiveness of alternative management strategies involving harvest regulations and river habitat improvement. The IPM classified individuals by body size, life history stage, and location relative to a hydropower dam, and was parameterised with $50 \mathrm{yr}$ of individual-based data, supplemented with literature values. Model simulations indicated a strong population decline of $22-29 \%$ per year without stocking, much of which was attributed to high harvest mortality. Consequently, drastic reductions in fishing pressure were predicted to be necessary to ensure population viability without stocking. Mitigation measures reducing mortality associated with the hydropower dam or restoring spawning areas could further contribute to population viability when combined with changes in harvest regulations. Our results thus emphasise that large changes in management strategies, such as termination of long-term stocking programmes, require a thorough assessment of potential consequences and alternative mitigation strategies using data and models, or, at the very least, a precautionary approach under consideration of on-going climate change.
\end{abstract}

KEY WORDS: Migratory salmonid · Salmo trutta $\cdot$ Integral projection model $\cdot$ Harvest $\cdot$ Fishing Stocking $\cdot$ Dam $\cdot$ Hydropower $\cdot$ Trout

\section{INTRODUCTION}

Freshwaters are amongst the most threatened ecosystems in the Anthropocene; rivers and lakes that have already been strongly impacted by centuries of

\footnotetext{
${ }^{*}$ Corresponding author: chloe.r.nater@ntnu.no
}

water pollution, flow modification, habitat destruction, overexploitation, and species invasions (Dudgeon et al. 2006) are now facing a whole new suite of emerging threats driven by large-scale climate change (Reid et al. 2019, Woolway \& Maberly 2020). Sustain- 
able management and conservation of freshwater species therefore hinge on a thorough understanding and joint mitigation of several interacting anthropogenic stressors.

Freshwater megafauna are intrinsically vulnerable to the interplay of anthropogenic stressors (He et al. 2019), and for economically valuable fish species, such as salmonids, large-scale stocking programmes have been used as a common mitigation measure for decades (Laikre et al. 2010, Aas et al. 2018). Stocking (or supplementation) programmes entail the release of captive-bred individuals to bolster recruitment and increase size, and often harvest yield, of wild populations (Naish et al. 2007, Laikre et al. 2010, Paquet et al. 2011). However, stocking programmes may have considerable adverse side effects on the genetic integrity of wild populations, potentially leading to loss of genetic variation through increased levels of inbreeding and breakdown of local adaptations over time (Laikre et al. 2010, Allendorf et al. 2013). Ultimately, this can lead to increased vulnerability to climate change (McGinnity et al. 2009) by reducing the potential for adaptation, thus making consideration of alternative and more sustainable management strategies paramount. The 2 main alternatives to stocking are (1) reducing fishing mortality through harvest regulations and (2) increasing natural production through improving and/or restoring habitat for wild populations (Arlinghaus et al. 2016). The relative effectiveness of different management strategies for any wild population depends on its reproductive capacity, the state of its habitat, and the total extent of harvest (Laikre et al. 2010, Rogers et al. 2010, Arlinghaus et al. 2016).

At the core of optimising management of harvested populations lie the quantitative analysis of population dynamics and the assessment of the relative importance of underlying mechanisms (Lorenzen 2005). While the ultimate goal of stocking, habitat restoration, and harvest regulation pertains to the population level, management interventions in practice affect individuals. Exploring the potential outcomes of management thus requires understanding effects on the vital rates of individuals, and how these translate into population dynamics (Williams et al. 2002). Moreover, individual responses, and their importance for population-level patterns, often vary depending on individual traits. Some of these traits are discrete (e.g. developmental stage, age), and matrix population models can account for among-individual variation in those (Caswell 2001). Harvested species, however, often encounter different risks based on a continuous trait: body size. Hunters, for example, may actively choose to kill a large animal (Festa-Bianchet \& Mysterud 2018), and most fishing gear is passively selective with regards to target body size (Jørgensen et al. 2009). Beyond harvest, body size is also an important determinant of individual survival and reproductive output in many species (Stearns 1992). Body size distribution can therefore have important consequences for the dynamics of harvested populations, making population models that are structured by continuous traits (e.g. integral projection models, Ellner \& Rees 2006) ideal tools for their study.

In the present study, we developed a size- and stage-structured integral projection model (IPM, Ellner \& Rees 2006) to investigate the combined effects of stocking, harvest, and river regulation on a population of landlocked, migratory brown trout Salmo trutta. Many populations of large brown trout in Norway have declined over the last decades due to overexploitation, hydropower production in spawning rivers, and habitat degradation (Museth et al. 2018). The study population has been subject to a largescale compensatory stocking programme for over half a century, but management authorities have recently suggested that the population may be viable without supplementary recruitment and that the stocking programme should be terminated to prevent further potential losses in genetic diversity. Here, we used the IPM parameterised with data collected over $50 \mathrm{yr}$ to (1) assess viability of a harvestable population in the absence of stocking, (2) investigate the relative importance of different mortality components across the entire life cycle, and (3) explore to what degree changes in harvest regulations, reductions in dam passage mortality, and improvement of spawning and recruitment areas compromised by hydropower production could compensate for the loss of captive-bred individuals.

\section{MATERIALS AND METHODS}

\subsection{Study system and data}

The study population of brown trout, locally referred to as 'Hunder trout', inhabits Lake Mjøsa and its main inlet river, Gudbrandsdalslågen, in eastern Norway. Despite being landlocked, Hunder trout closely resemble migratory sea trout Salmo trutta and Atlantic salmon $S$. salar in terms of body size and life history (Aass et al. 1989; Fig. 1). Adult Hunder trout spawn in the river in fall, and the eggs overwinter in loose gravel and hatch the following spring. Newly hatched trout spend $3-5 \mathrm{yr}$ in the river as juveniles 


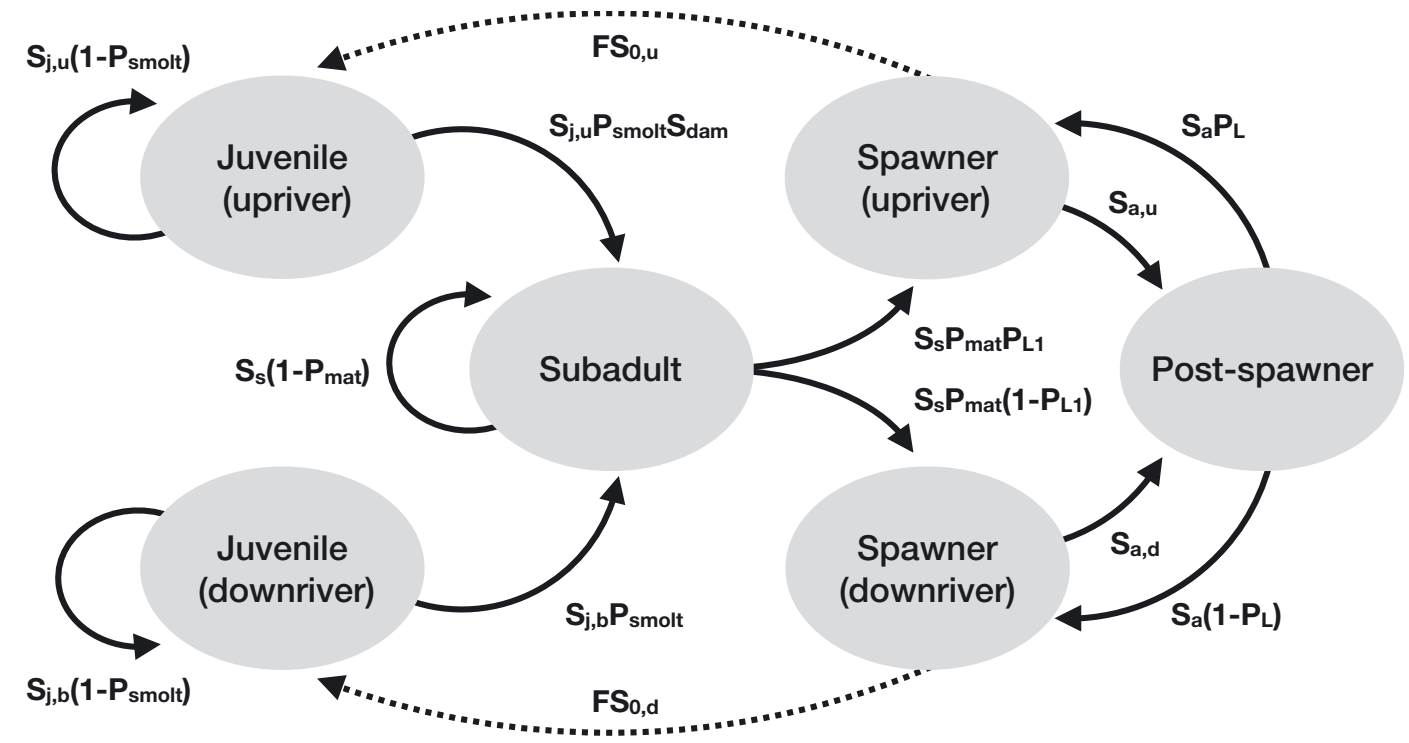

Fig. 1. Life cycle of the Hunder trout as formulated in the integral projection model. Arrows represent the possible annual transitions from the start of the spawning migration in year $t$ to the start of the spawning migration in year $t+1$. Arrows are annotated with transition probabilities based on various vital rates, with solid arrows representing survival and life-history transitions and dotted arrows representing reproduction (see Table 2)

before smolting and migrating downriver into the lake at an average length of $250 \mathrm{~mm}$. After $2-3 \mathrm{yr}$ of piscivorous diet resulting in fast growth in the lake, they mature at an average length of $630 \mathrm{~mm}$ and migrate back up the river to spawn. Following the first spawning run, mature fish alternate between spawning and resting years, resulting in a biennial spawning cycle.

A hydropower dam constructed in the river in the 1960s clearly divides the spawning and recruitment areas of Hunder trout into an upriver section (above the dam), accessible for spawning trout via a fish ladder, and a downriver section (below the dam). The latter has restricted water flow and availability of suitable spawning sites, which may severely limit reproductive success and recruitment (Kraabøl 2006). To compensate for expected adverse effects of the dam on production and harvest yield, a large-scale stocking programme was initiated immediately following dam construction (Aass 1993). After an initial experimental phase (1960s and 1970s), the stocking strategy was standardised in 1984. Since then, $20000-40000$ smolts ( $2 \mathrm{yr}$ old) with an average size of $200-240 \mathrm{~mm}$ have been released annually in several locations in the river (up- and downriver of the dam) and the lake. Stocked fish have constituted up to $\sim 60 \%$ of the spawning population in more recent years (Moe et al. 2020).

The Hunder trout population was monitored extensively between 1966 and 2016. During this period, all adult trout ascending the fish ladder at the Hunderfossen dam were captured and individually marked. Marked trout were recaptured and reported both in the fish ladder during later spawning runs and by fishers following harvest. The resulting markrecapture-recovery data span $51 \mathrm{yr}$ and close to 15000 individuals. For around 7000 of these individuals, additional individual-level data on growth histories and life history schedules (smolting and spawning events) were obtained through sclerochronological analysis of scales collected in the fish ladder at marking. For detailed descriptions of data sets and sampling protocols, see Moe et al. (2020).

To supplement the long-term data sets, we collected a limited amount of individual-based data on fecundity during the spawning seasons of 2017 and 2018. Female trout were captured in the fish ladder, kept in pools until ready to spawn, and subsequently handstripped. For a total of 15 females (6 in 2017, 9 in 2018) we then measured body length and calculated the total number of eggs based on egg-weight estimates from 3 sub-samples of the total batch.

\subsection{Size-structured population model}

Based on the Hunder trout life cycle (Fig. 1), we built an IPM structured by both life stage (representing life history stage and spawning status) and body size (fork length, in $\mathrm{mm}$ ). The model is female-based and density-independent, and all vital rates across the life cycle are modelled as functions of body size (see Supplement 2 at www.int-res.com/articles/suppl/ cr01644_supp.pdf). The annual census is placed right after the trout have begun their spawning migration and entered the river in late summer. 
Matrix 1. Projection matrix. Details described in Section 2.2

\begin{tabular}{|c|c|c|c|c|c|c|c|}
\hline & \multicolumn{6}{|c|}{ stage $j(t)$} \\
\hline & & $J u v(u)$ & $J u v(d)$ & Sub & $\operatorname{Sp}(u)$ & $S p(d)$ & PSp \\
\hline \multirow{6}{*}{ 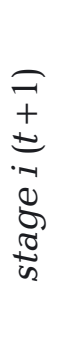 } & $J u v(u)$ & $K_{J J}\left(x^{\prime}, x, u\right)$ & 0 & 0 & $K_{J S p}\left(x^{\prime}, X_{1} u\right)$ & 0 & 0 \\
\hline & $J u v(d)$ & 0 & $K_{J J}\left(x^{\prime}, x, d\right)$ & 0 & 0 & $K_{J S p}\left(x^{\prime}, x_{1} d\right)$ & 0 \\
\hline & Sub & $K_{S J}\left(x^{\prime}, X, u\right)$ & $K_{S J}\left(x^{\prime}, x, d\right)$ & $K_{S S}\left(x^{\prime}, x\right)$ & 0 & 0 & 0 \\
\hline & $S p(u)$ & 0 & 0 & $K_{S p S}\left(x^{\prime}, x, u\right)$ & 0 & 0 & $K_{S p P}\left(\boldsymbol{x}^{\prime}, \mathbf{x}, u\right)$ \\
\hline & $S p(d)$ & 0 & 0 & $K_{S p S}\left(x^{\prime}, x_{1} d\right)$ & 0 & 0 & $K_{S p P}\left(x^{\prime}, x, u\right)$ \\
\hline & $P S p$ & 0 & 0 & 0 & $K_{P S p}\left(x^{\prime}, x, u\right)$ & $K_{P S p}\left(x^{\prime}, x, u\right)$ & 0 \\
\hline
\end{tabular}

The transitions from life stages $j$ in the current year $t$ to life stages $i$ in the next year $t+1$ are described by a projection matrix (Matrix 1 above) consisting of size-structured transition kernels $K_{i j}$ (which, in turn, are made up of a sequence of size-dependent vital rates, Tables $1 \& 2$ ). In Matrix 1, $x$ is the initial size prior to the growth season of the current year $(t)$ and $x^{\prime}$ is the next size reached at the end of the current year's growth season (and therefore also the initial size for the next year $t+1$ ). The indicator variables $u$ and $d$ denote the location of juveniles and spawners as up- or downriver of the dam, respectively. In the following, we also use $z$ (in place of $d$ or $u$ ) when referring to individuals in either location.

$K_{J S p}\left(X^{\prime}, X, u\right)$ and $K_{J S p}\left(X^{\prime}, X, d\right)$ are the reproduction kernels upriver and downriver of the dam respectively, and consist of the fecundity of a female of size $x(F(x))$, multiplied by 0.5 to represent only female offspring, the location-specific early survival $\left(S_{0, z}\right)$ from egg to $1 \mathrm{yr}$ old, and an offspring size distribution at age 1 independent of the size of the mother $\left(f\left(x^{\prime}\right)\right)$. The production of age 1 offspring of size $x^{\prime}$ in location $z$ by females of size $x$ is thus described as:

$$
K_{J S p}\left(x^{\prime}, x, z\right)=0.5 F(x) S_{0, z} f\left(x^{\prime}\right)
$$

All other kernels consist of survival and growth components, as well as pre- and/or post-growth transition components (Table 1). For example, the kernel for the transition from subadult to upriver spawner is defined as:

$$
K_{S p S}\left(x^{t}, x, u\right)=S_{s}(x) P_{m a t}(x) g_{L}\left(x^{i}, x\right) P_{L}\left(x^{\prime}\right)
$$

To become an upriver spawner within a year starting in late summer, a subadult individual first survives $\left(S_{s}(x)\right)$ and matures $\left(P_{\text {mat }}(x)\right.$, pre-growth stage transition) depending on its current body size $x$. It then grows from size $x$ to size $x^{\prime}$ before the next late summer census $\left(g_{L}\left(x^{\prime}, x\right)\right)$, and subsequently uses the fish ladder depending on its newly attained size $x^{\prime}\left(P_{L}\left(x^{\prime}\right)\right.$, post-growth stage transition). All kernels and kernel components are defined in Tables $1 \& 2$. Survival probabilities are expressed in terms of time-averaged mortality hazard rates (Ergon et al. 2018).

Using the kernel components of the projection matrix (Matrix 1), the population projection from one time step to the next is done by integrating over all sizes and summing over all stages (Ellner \& Rees 2006):

$$
n_{i}\left(x^{\prime}, t+1\right)=\sum_{j=1}^{\Omega} \int_{L}^{U} K_{i j}\left(x^{\prime}, x\right) n_{j}(x, t) \mathrm{d} x
$$

where $n_{j}(x, t)$ is the density of individuals of size $x$ in life stage $j$ at time $t, \Omega$ is the number of life stages, and $L$ and $U$ are the lower and upper size limits, respectively.

Here, we first build the IPM projection kernel for a size range from $L=0$ to $U=1300 \mathrm{~mm}$. We then discretise the kernel by dividing the size range into 300 bins of $4.33 \mathrm{~mm}$ (an adequate resolution to obtain accurate results from our model). The resulting stageby-size bin projection matrix forms the basis for all subsequent analyses. We obtained the size-vital rate relationships necessary to parameterise the IPM projection kernel from several sources. We calculated size-dependent growth $\left(g_{R}\left(x^{\prime}, x\right)\right.$ and $\left.g_{L}\left(x^{\prime}, x\right)\right)$, adult mortality $\left(m^{H}(x)\right.$ and $\left.m_{a, z}^{\circ}(x)\right)$, and ladder usage probability $\left(P_{L}(x)\right)$ using posterior means from the models of Nater et al. $(2018,2020 b)$. For size-dependent smolting $\left(P_{\text {smolt }}(x)\right)$ and maturation $\left(P_{\text {mat }}(x)\right)$ probabilities, we used point estimates from generalised linear mixed models fit to individual-level scale data. Size-dependent fecundity $(F(x))$ was estimated from the egg count data collected in 2018 and 2019, and all remain- 
Table 1. Overview of the composition of all transition kernels. $x$ and $x^{\prime}$ represent current and next size, respectively. $u$ and $d$ indicate upriver and downriver of the dam, respectively. Vital rates listed under 'Kernel composition' are defined in Table 2

\begin{tabular}{|c|c|c|}
\hline Stage transition & Transition kernel & Kernel composition \\
\hline Juvenile-Juvenile & $\begin{array}{l}K_{J J}\left(x^{\prime}, X, u\right) \\
K_{J J}\left(x^{\prime}, X, d\right)\end{array}$ & $\begin{array}{l}=S_{j, u}(x)\left[1-P_{\text {smolt }}(x)\right] g_{R}\left(x^{\prime}, x\right) \\
=S_{j, d}(x)\left[1-P_{\text {smolt }}(x)\right] g_{R}\left(x^{\prime}, x\right)\end{array}$ \\
\hline Juvenile-Subadult & $\begin{array}{l}K_{S J}\left(x^{\prime}, x, u\right) \\
K_{S J}\left(x^{\prime}, x, d\right)\end{array}$ & $\begin{array}{l}=S_{j, u}(x) P_{\text {smolt }}(x) S_{d a m}(x) g_{L}\left(x^{\prime}, x\right) \\
=S_{j, d}(x) P_{\text {smolt }}(x) g_{L}\left(x^{\prime}, x\right)\end{array}$ \\
\hline Subadult-Subadult & $K_{S S}\left(x^{\prime}, x\right)$ & $=S_{S}(x)\left[1-P_{m a t}(x)\right](x) g_{L}\left(x^{\prime}, x\right)$ \\
\hline Subadult-Spawner & $\begin{array}{l}K_{S p S}\left(\boldsymbol{X}^{\prime}, \boldsymbol{X}, u\right) \\
K_{S p S}\left(\boldsymbol{X}^{\prime}, \boldsymbol{X}, \boldsymbol{d}\right)\end{array}$ & $\begin{array}{l}=S_{S}(x) P_{\text {mat }}(x)(x) g_{L}\left(x^{\prime}, x\right) P_{L}\left(x^{\prime}\right) \\
=S_{S}(x) P_{\text {mat }}(x)(x) g_{L}\left(x^{\prime}, x\right)\left[1-P_{L}\left(x^{\prime}\right)\right]\end{array}$ \\
\hline Spawner-Juvenile & $\begin{array}{l}K_{J S p}\left(x^{\prime}, X, u\right) \\
K_{J S p}\left(x^{\prime}, X^{\prime} d\right)\end{array}$ & $\begin{array}{l}=0.5 F(x) S_{0, u} f\left(x^{\prime}\right) \\
=0.5 F(x) S_{0, d} f\left(x^{\prime}\right)\end{array}$ \\
\hline Spawner-Post-spawner ${ }^{a}$ & $\begin{array}{l}K_{P S p}\left(x^{\prime}, x, u\right) \\
K_{P S p}\left(x^{\prime}, x, d\right)\end{array}$ & $\begin{array}{l}=S_{a, u}(x) g_{L}\left(x^{\prime}, x\right) \\
=S_{a, d}(x) g_{L}\left(x^{\prime}, x\right)\end{array}$ \\
\hline Post-spawner-Spawner ${ }^{\mathrm{b}}$ & $\begin{array}{l}K_{S p P}\left(x^{\prime}, \mathbf{x}, u\right) \\
K_{S p P}\left(x^{\prime}, \mathbf{x}, d\right)\end{array}$ & $\begin{array}{l}=S_{a, u}(x) g_{L}\left(x^{\prime}, x\right) P_{L}\left(x^{\prime}\right) \\
\left.=S_{a, d}(x) g_{L}\left(x^{\prime}, x\right)\left[1-P_{L}\left(x^{\prime}\right)\right)\right]\end{array}$ \\
\hline \multicolumn{3}{|c|}{${ }^{\mathrm{a}} S_{a, u}$ and $S_{a, d}$ represent survival over $2 \mathrm{yr},{ }^{\mathrm{b}} S_{a, u}$ and $S_{a, d}=1$} \\
\hline
\end{tabular}

ing size-vital rate relationships were inferred from the literature (see Supplement 3). Relevant parameters estimated from long-term data $\left(m^{H}(x), m_{a, z}^{\circ}(x)\right.$, $P_{L}(x), P_{\text {mat }}(x)$, and $\left.g_{L}\left(x^{\prime}, x\right)\right)$ were further estimated separately for stocked and wild-born individuals, but resulting differences due to origin were small
(Fig. S2.5 in Supplement 2). Vital rate estimation and IPM parameterisation are described in greater detail in Supplement 2.

\subsection{Scenarios and analyses}

\subsubsection{Impact of the dam on reproduction}

Potential reductions in recruitment below the dam (due to less available/suitable spawning areas) are important to consider when assessing population viability. Given the lack of empirical estimates of reproductive success above and below the dam, we adopted an explorative approach in which we introduced a 'below-dam penalty' on early mortality (= egg to 1 yr old) downriver of the dam $\left(m_{0, d}\right)$. Specifically, we ran all of the following analyses for 3 scenarios: (1) no penalty $\left(m_{0, d}=m_{0, u}\right)$, (2) $50 \%$ higher early mortality below the dam $\left(m_{0, d}=1.5 \times m_{0, u}\right.$, hereafter 'moderate penalty'), and (3) $100 \%$ higher early mortality below the dam $\left(m_{0, d}=2 \times m_{0, u}\right.$, hereafter 'high penalty' $)$.

Table 2. Summary of vital rates used in the population model. All functions for survival probabilities are formulated using time-averaged mortality hazard rates

\begin{tabular}{|c|c|c|}
\hline Model components & Vital rate ${ }^{a}$ & Description $^{\mathrm{a}}$ \\
\hline Survival & $\begin{array}{l}S_{j, z}(x) \\
S_{d a m}(x) \\
S_{S}(x) \\
S_{a, z}(x) \\
m_{j, z}(x) \\
m_{d a m}(x) \\
m^{H}(x) \\
m_{S}^{\circ}(x) \\
m_{a, z}^{\circ}(x)\end{array}$ & $\begin{array}{l}\text { Survival probability of juveniles of size } x \text { in location } z_{i}=\exp \left[-m_{j, z}(x)\right] \\
\text { Dam survival probability of smolts of size } x_{i}=\exp \left[-m_{d a m}(x)\right] \\
\text { Survival probability of subadults of size } x_{i}=\exp \left[-\left(m^{H}(x)+m_{S}^{\circ}(x)\right)\right] \\
\text { Survival probability of adults of size } x \text { spawning in location } z_{i}=\exp \left[-\left(m^{H}(x)+m_{a, z}^{\circ}(x)\right)\right] \\
\text { Mortality hazard rate of juveniles of size } x \text { in location } z \\
\text { Dam mortality hazard rate of smolts of size } x \\
\text { Harvest mortality hazard rate of subadults and adults of size } x \\
\text { Background mortality hazard rate of subadults of size } x \\
\text { Background mortality hazard rate of adults of size } x \text { spawning in location } z\end{array}$ \\
\hline Growth & $\begin{array}{l}g_{R}\left(x^{\prime}, x\right) \\
g_{L}\left(x^{\prime}, x\right)\end{array}$ & $\begin{array}{l}\text { Probability of juveniles of size } x \text { to grow to size } x^{\prime} \text { in the river } \\
\text { Probability of subadults and adults of size } x \text { to grow to size } x^{\prime} \text { in the lake }\end{array}$ \\
\hline $\begin{array}{l}\text { Pre-growth stage } \\
\text { transition }\end{array}$ & $\begin{array}{l}P_{\text {smolt }}(\mathrm{X}) \\
P_{\text {mat }}(\mathrm{X})\end{array}$ & $\begin{array}{l}\text { Smolting probability of juveniles of size } x \\
\text { Maturation probability of subadults of size } x\end{array}$ \\
\hline $\begin{array}{l}\text { Post-growth stage } \\
\text { transition }\end{array}$ & $P_{L}\left(x^{\prime}\right)$ & Ladder usage probability of subadults and transition adults after having grown to size $x^{\prime}$ \\
\hline Reproduction & $\begin{array}{l}F(x) \\
S_{0, z} \\
m_{0, z} \\
f\left(x^{\prime}\right)\end{array}$ & $\begin{array}{l}\text { Fecundity of adults of size } x \\
\text { Early (egg to juvenile) survival probability in location } z_{i}=\exp \left[-m_{0}\right] \\
\text { Early (egg to juvenile) mortality hazard rate in location } z \\
\text { Size distribution of recruits in fall }\end{array}$ \\
\hline
\end{tabular}




\subsubsection{Population dynamics under stocking}

To contrast population dynamics with and without stocking, we extended the population model to include stocked smolt. These were added as individuals recruiting into the subadult stage with a given size distribution (see Supplement 4) via immigration at the same time as the wild-born fish enter this stage via smolting (Fig. 1). Like their wild-born counterparts, stocked individuals may die while passing the dam depending on their size $x$ (with probability $1-S_{\text {dam }}(x)$ ) if released upriver, and survivors will then grow to size $x^{\prime}$ before the next census. The hatchery-to-subadult transition kernel for stocked fish released upriver $(u)$ and downriver $(d)$ of the dam are formulated as:

$$
\begin{gathered}
K_{H S}\left(x^{\prime}, x, u\right)=S_{d a m}(x) g_{L}\left(x^{\prime}, x\right) \\
K_{H S}\left(x^{\prime}, x, d\right)=g_{L}\left(x^{\prime}, x\right)
\end{gathered}
$$

The next year's size distribution of subadults is then given by:

$$
\begin{gathered}
n_{S}\left(x^{\prime}, t+1\right)=\sum_{j=1} \int_{L}^{U} K_{j S}\left(x^{\prime}, x\right) n_{j}(x, t) \mathrm{d} x+ \\
\int_{L}^{U} K_{H S}\left(x^{\prime}, x, u\right) n_{H}(x, u, t) \mathrm{d} x+\int_{L}^{U} K_{H S}\left(x^{\prime}, x, d\right) n_{H}(x, d, t) \mathrm{d} x
\end{gathered}
$$

The first argument on the right-hand side of Eq. (5) represents all wild-born juveniles smolting and becoming subadults, while the second and third argument are the subadults that were released from the hatchery up- and downriver of the dam, respectively. We calculated the mean annual number of stocked smolt of size $x$ released at location $z\left(n_{H}(x, z, t)\right)$ from annual smolt release reports (1984-2017, see Supplement 4 for details). For projecting the population under stocking, we further split the IPM into separate projection matrices for wild-born and stocked individuals, each of which used origin-specific prediction functions for harvest mortality, adult background mortality, lake growth, maturation probability, and ladder usage probability (Fig. S2.5 in Supplement 2).

Using this extended model, we were able to simulate the consequences of terminating the stocking programme on population dynamics. We did this by first projecting the population with stocking for $200 \mathrm{yr}$ (starting from the stable size-by-stage distribution, Fig. S1.2 in Supplement 1), and then continued the projection for another $200 \mathrm{yr}$ without stocking.

\subsubsection{Sensitivity to mortality components}

We evaluated the sensitivity of population metrics $(M)$ to changes in the different mortality components.
For $M$, we chose asymptotic population growth rate $\lambda$ for scenarios without stocking (the dominant right eigenvalue of the projection matrix, Caswell 2001) and equilibrium population size after 200 projection steps for scenarios with stocking. We calculated sensitivities using a perturbation approach: we added a small number a $\left(=1 \times 10^{-5}\right)$ to one mortality hazard rate at a time, built the projection matrix (Matrix 1) with the perturbed hazard rate, extracted the metric under perturbation $\left(M_{\text {pert }}\right)$, and compared it to the metric without perturbation $\left(M_{\text {orig }}\right)$. We then calculated sensitivity of $M$ to the mortality hazard rate in question as: $\frac{M_{\text {pert }}-M_{\text {orig }}}{a}$. Analogously, we calculated elasticities (i.e. proportional sensitivities) as: $\frac{M_{\text {pert }}-M_{\text {ori }}}{a M}$, after multiplying mortality hazard rates by $1+a$.

For stocked and unstocked populations, we separated the sensitivities to mortality hazard rates of up- and downriver juveniles and spawners to evaluate how the dam affected contributions. For stocked populations, we further distinguished the mortality components of stocked versus wild-born individuals.

\subsubsection{Mitigation measures in the absence of stocking}

Termination of stocking results in a loss of artificial recruitment, and other mitigation measures may be necessary to compensate for this. As a first step towards evaluating the potential of compensatory mitigation measures, we explored the effect of 4 different harvest strategies: (1) no harvest $\left(m^{H}=0\right)$, (2) minimum size limit protecting small individuals $\left(m^{H}=0\right.$ for $\left.x<500 \mathrm{~mm}\right)$, (3) maximum size limit protecting large individuals $\left(m^{H}=0\right.$ for $\left.x>700 \mathrm{~mm}\right)$, and (4) harvest slot regulation to protect both small and large individuals $\left(m^{H}=0\right.$ for $\left.500<x<700 \mathrm{~mm}\right)$. We evaluated the viability of the trout population under these 4 strategies by looking at responses of $\lambda$ and long-term projections following termination of stocking.

Next, we explored the population response to decreases in total harvest mortality (all sizes) ranging from 0 to $100 \%$ reduction, in combination with a second type of mitigation measure: reducing the dam passage mortality of smolts and/or upriver spawners on their lake-wards migration, or reducing the background mortality of downriver spawners. For the dam mortality of smolts, we compared an unperturbed scenario (no change in $m_{d a m}$ ) to a scenario where all smolts survived dam passage $\left(m_{d a m}=0\right)$. For dam mortality of upriver spawners, we used a dif- 
ferent approach since dam mortality is not an explicit parameter in our population model but contained in the estimate of adult background mortality $\left(m_{a, u}^{\circ}\right)$. With currently available data, it was impossible to determine what part of the estimated $m_{a, u}^{o}$ is due to passing the dam. However, Nater et al. (2020b) suggested that the higher mortality of smaller abovedam spawners may be due to the dam, as they are more likely to enter the turbines on their downriver migration. With that in mind, we designed exploratory scenarios of reduced dam mortality of upriver spawners by reducing the increase of $m_{a, u}^{\circ}$ with body size for smaller than average $(x<670 \mathrm{~mm})$ individuals by $0-100 \%$. To simulate reductions in belowdam spawner mortality, we decreased total background mortality for all sizes by $0-100 \%$. We then built projection matrices and calculated $\lambda$ for the range of possible combinations of restricted harvest in combination with reductions in (1) spawner dam passage mortality, (2) spawner and smolt dam passage mortality, and (3) below-dam spawner mortality (= 2601 scenarios each; each mortality reduction ranging from 0 to $100 \%$ at $2 \%$ intervals).

\section{RESULTS}

\subsection{Population dynamics with and without stocking}

With stocking in place, the population was projected to converge towards a stable equilibrium pop-

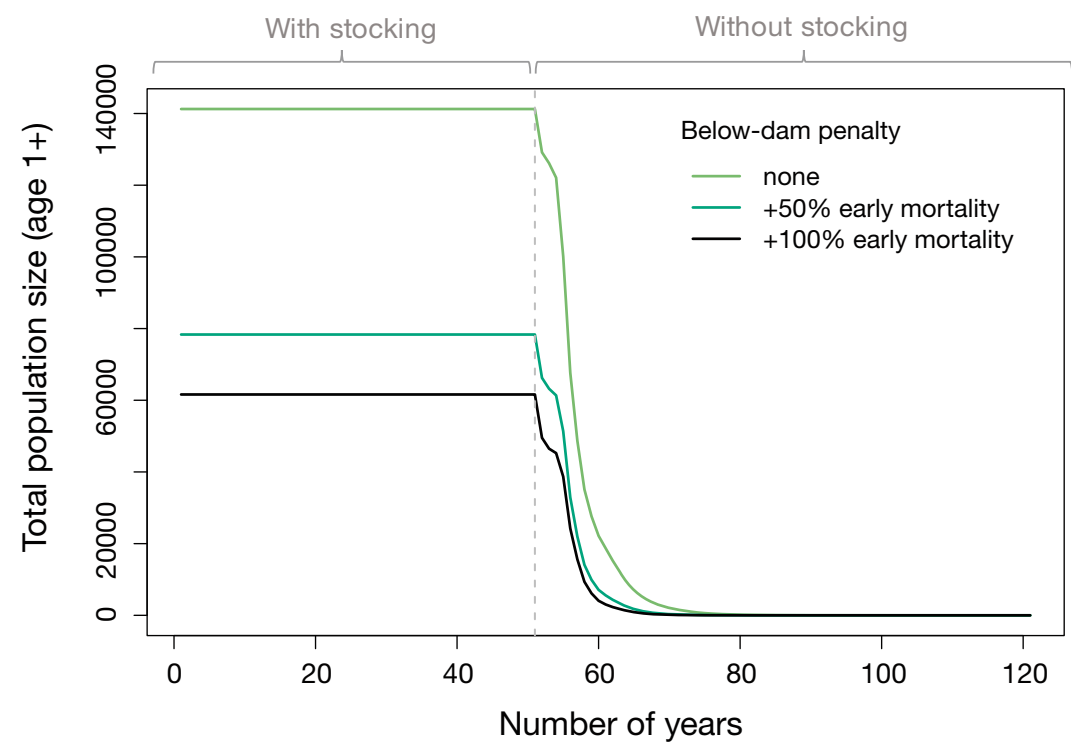

Fig. 2. Projection of the Hunder trout population with (up to year $50=$ dashed line) and without stocking, and assuming either no below-dam penalty (light green), or below-dam penalties of $50 \%$ (turquoise) and $100 \%$ (black) higher early mortality ulation size, which depended strongly on the severity of the below-dam penalty on early survival (Fig. 2). In the absence of stocking, the population declined rapidly towards extinction irrespective of whether reproductive output below the dam was penalised or not (Fig. 2). Here, the long-term growth rate $\lambda$ took values of 0.784 when assuming no below-dam penalty, 0.732 with a moderate below-dam penalty, and 0.706 with a severe below-dam penalty. With or without stocking, juveniles made up the largest part of the population (72-96\%). The higher the belowdam penalty, the larger was the proportion of juveniles up- relative to downriver of the dam. Subadults and small spawners made up a larger segment of the population when stocking was included (Fig. S1.2 in Supplement 1).

\subsection{Relative importance of mortality components}

Overall, changes in harvest mortality were predicted to have the strongest impacts on population dynamics both with and without stocking (Fig. 3; Fig. S1.4 in Supplement 1). With stocking, the sensitivity and elasticity of equilibrium population size to harvest mortality were 13-50\% higher than those of the next-ranking components (subadult background and early mortality; Fig. 3a; Fig. S1.4a in Supplement 1). The dynamics of stocked populations were also overall more sensitive to mortality of stocked than wild-born individuals (Fig. S1.3 in Supplement 1). In the absence of stocking, changes in components other than harvest (especially those involved in recruitment, i.e. $m_{0}$ and $m_{j}$ ) were predicted to have relatively more influence, and their relative importance depended substantially on the degree to which recruitment below the dam was assumed to be compromised (Fig. 3b; Fig. S1.4b in Supplement 1).

\subsection{Responses to mitigation measures}

Mitigation measures involving changes in harvest regulations had strong impacts on predicted population viability in the absence of stocking (Fig. 4). Completely abolishing harvest led to a $\sim 40 \%$ increase in $\lambda$ irrespective of below-dam penalty (Table S1.1 in 
a

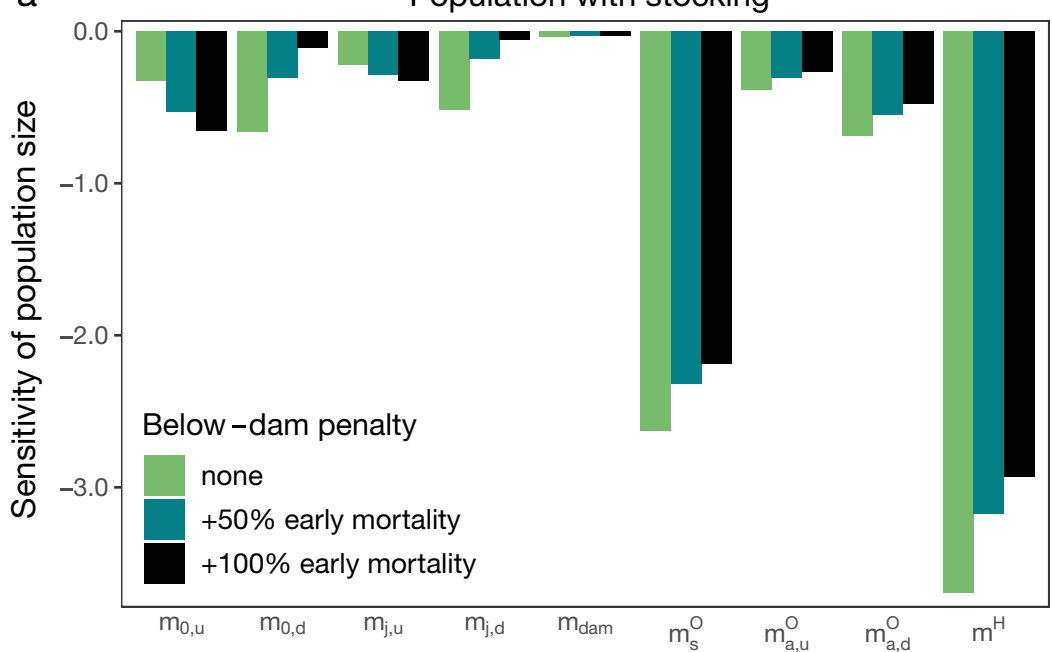

b

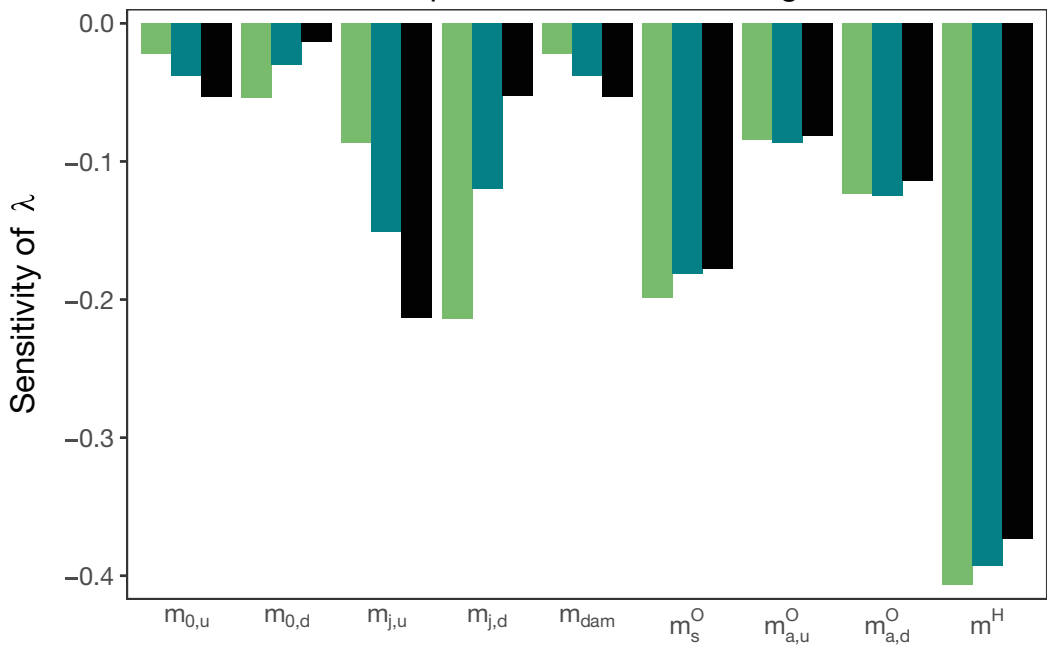

Fig. 3. Sensitivity of (a) equilibrium population size in a population with stocking and (b) asymptotic population growth rate $\lambda$ in a population without stocking to different mortality hazard rates (see Table 2 for parameter definitions)

Supplement 1). This resulted in a growing population when there was either no (Fig. 4a) or only a moderate below-dam penalty (Fig. S1.5 in Supplement 1). Sparing only a part of the population based on their body size had smaller impacts, leading to $\sim 11 \%$ higher $\lambda$ when both small $(>500 \mathrm{~mm}$ ) and large $(>700 \mathrm{~mm}$ ) individuals were protected. Sparing small individuals was slightly more efficient than sparing large individuals when there was either no or a severe below-dam penalty, whereas the 2 strategies had more similar outcomes when assuming a moderate below-dam penalty (Table S1.1 in Supplement 1). Mitigation measures protecting all or only large individuals further resulted in higher proportions of large-sized individuals within populations (Fig. 4b).
Scenarios involving proportional decreases in harvest mortality (but no supporting measures) revealed that even in the best case (i.e. no belowdam penalty), a reduction of harvest mortality by around $76 \%$ was necessary to prevent population decline (Fig. 5). Assuming a moderate below-dam penalty, the population was viable in the absence of stocking only if total harvest was reduced by at least $96 \%$ (Fig. S1.6b in Supplement 1). Finally, if the below-dam penalty was severe, even completely abolishing harvest was insufficient to sustain the population (Fig. S1.6c in Supplement 1). Simultaneously decreasing either dam passage mortality of spawners or background mortality below the dam had only small effects in comparison, but combined measures led to higher $\lambda$ than harvest measures alone (Figs. 5; Figs. S1.6 \& S1.8 in Supplement 1). Additionally reducing dam mortality of smolts to 0 had negligible effects, increasing $\lambda$ by $0.86 \%$ (no below-dam penalty) to $2.18 \%$ (severe below-dam penalty) on average (Fig. S1.7 in Supplement 1).

\section{DISCUSSION}

\subsection{Harvest as a key driver of population dynamics}

Long-term projections from our model showed that with regular stocking, the trout population stabilised at an equilibrium size which depended strongly on the number of stocked fish added annually and the capacity for natural recruitment below the dam (Fig. 2). Without stocking, the population was unable to maintain its current size and was projected to drop to critically low levels within less than $30 \mathrm{yr}$ in the best scenario, thus closely resembling the dynamics of other landlocked salmonids exposed to multiple human disturbances (Whelan \& Johnson 2004, Brown et al. 2013). Post et al. (2003) noted that populations of landlocked migratory salmonids can only tolerate low levels of harvest due to their slow life histories, and the present study supports this by revealing a strong sensitivity to harvest relative to other sources 
a

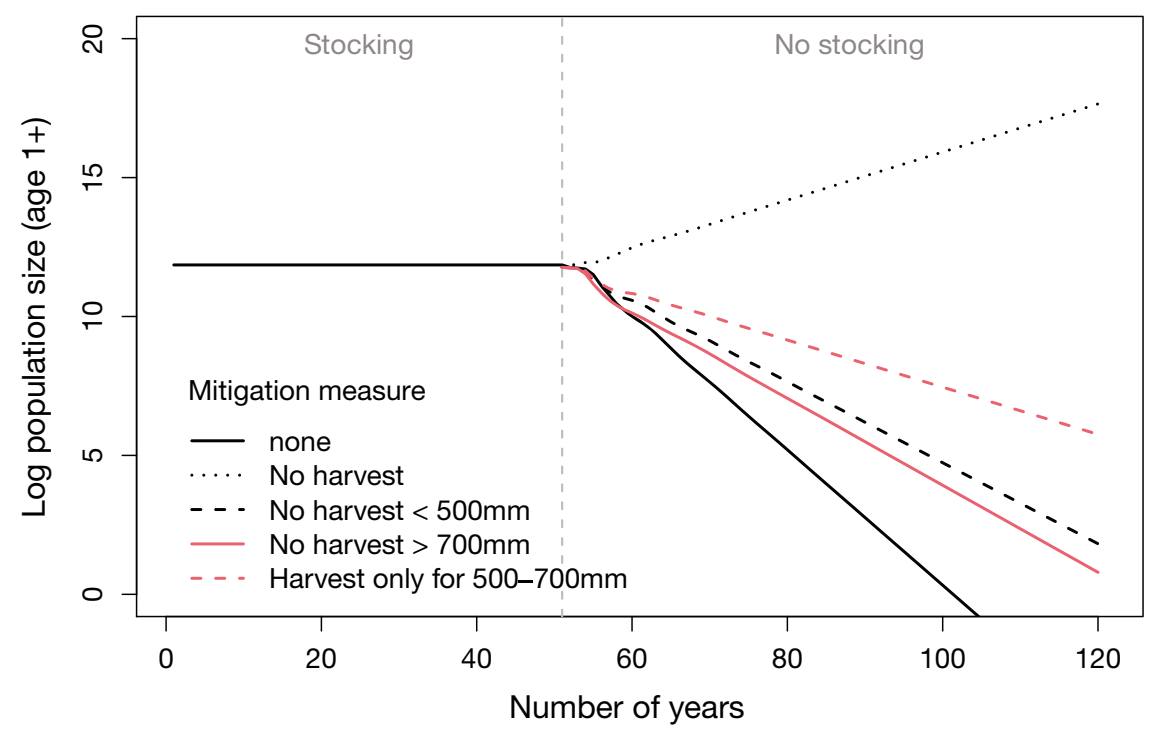

b

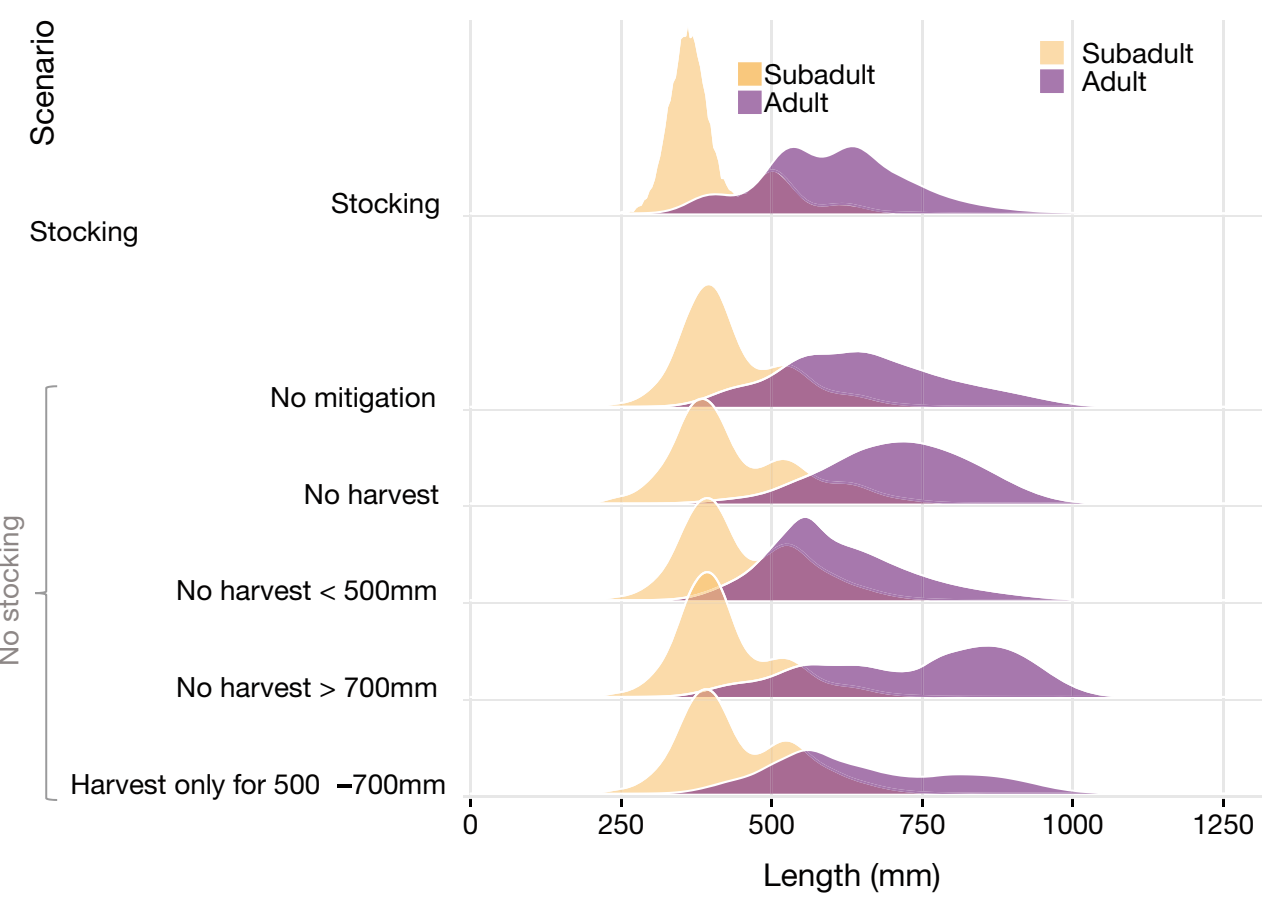

Fig. 4. Projection of (a) trout population size (log-scale) and (b) size distributions within subadult and adult stages (spawners and post-spawners) with and without stocking and complementary mitigation measures (no below-dam penalty). Size distributions in (b) are scaled to sum to 1 within stages, representing relative, not total, density

of mortality (Fig. 3). The fundamental link between the speed of life history and vulnerability to harvest is well established for fish in general (Hutchings \& Reynolds 2004), as well as for other taxonomic groups (Reynolds et al. 2001), and is a consequence of populations being unable to replace the older, larger individuals targeted by harvest fast enough. In agreement with this, our sensitivity analysis also showed that without stocking, mortality components across the entire life cycle were highly influential (Fig. 3b; Fig. S1.4b in Supplement 1). Population dynamics with stocking, on the other hand, were driven predominantly by harvest and background mortality of subadults (Fig. 3a). This mirrors the fact that in the stocked population, newly released subadults represent the majority of the recruitment 


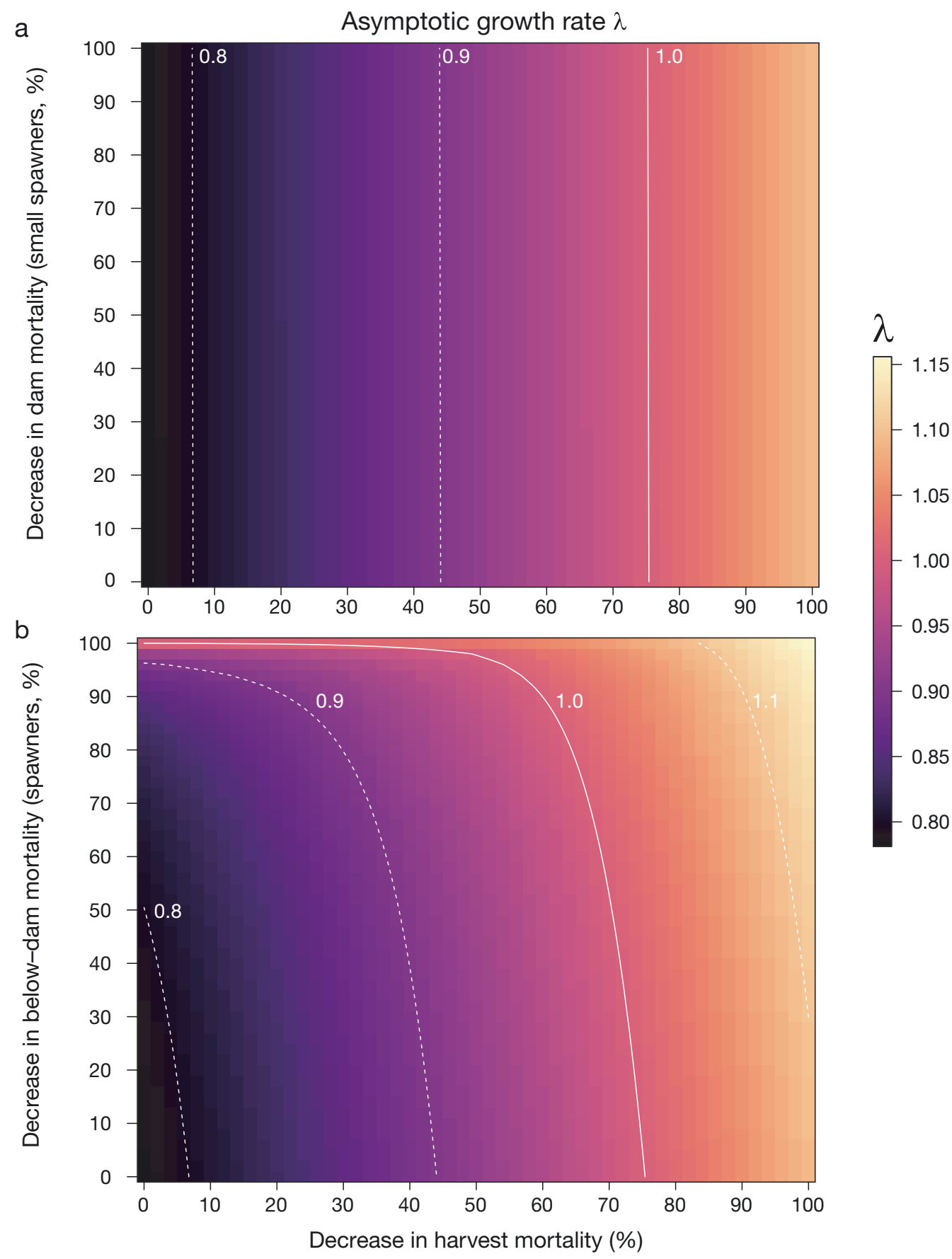

Fig. 5. Asymptotic population growth rate $\lambda$ calculated from the projection matrix (Matrix 1) under different reductions of harvest mortality ( $x$-axis) and (a) dam passage mortality of spawners (approximated as decreases in background mortality of below average-sized above-dam spawners) or (b) background mortality of below-dam spawners ( $y$-axis). White lines mark $\lambda=1$ (solid) and $\lambda=0.8,0.9,1.1$ (dashed)

and make up a considerable part of the population (Figs. S1.2 \& S1.3 in Supplement 1). While these sensitivity patterns apply to the population under average conditions, we note that the relative roles of different mortality components for population dynamics may indeed be variable over time, and could even change in a directional manner if intense harvest was driving evolutionary changes (Heino et al. 2015). Fisheries-induced evolution is predicted to speed up life histories, and observations of trends towards ear- 
lier maturation and smaller size-at-age in the Hunder trout may indicate involvement of evolutionary processes. Recent evaluations have shown that the effects of fisheries-induced evolution on population growth rate and population persistence and recovery are negligible (Kuparinen \& Hutchings 2012, Hutchings \& Kuparinen 2020). Since the present study focusses primarily on precisely these quantities, the general conclusions are likely robust to unaccountedfor fisheries-induced evolution on time-scales relevant for management. Nonetheless, potential longterm life-history changes can be relevant in the context of preserving both ecological function and cultural value of large freshwater fishes (Whelan \& Johnson 2004, Ohlberger et al. 2014, He et al. 2019, Ohlberger et al. 2020) and should be included in ecoevolutionary studies aimed at designing sustainable management strategies (see Section 4.4).

\subsection{Relative effects of different harvest regulations}

The overall high sensitivity of population dynamics to harvest (Fig. 3), and the fact that harvest mortality, unlike most other types of mortality, can be targeted by management intervention directly, make harvest regulations a key mechanism for ensuring population viability. Under the strict assumptions of the current model, we found that the total harvest mortality of fish of all sizes would have to be reduced by 76-100\% (depending on natural recruitment capacity) to sustain a population in the long run without stocking and in the absence of other mitigation measures (Fig. 5; Fig. S1.5 in Supplement 1). At the same time, this would lead to higher proportions of ecologically valuable, large-sized individuals in the population (Fig. 4b; Whelan \& Johnson 2004, Ohlberger et al. 2014). In practice, however, reductions in total harvest mortality of such magnitude would likely have to be achieved by drastically limiting not only each individual fisher's catch (e.g. with bag limits) but also the total fishing effort (e.g. by restricting the number of fishers, Post et al. 2003). Policy interventions such as these, which place strong limitations on the activity of fishers, tend to be faced with strong opposition and may thus be hard to implement and enforce (Arlinghaus et al. 2002). This is likely also the case for the fishery of the Hunder trout, which not only has a long history (Huitfeldt-Kaas 1916, Aass \& Kraabøl 1999) but is also very popular today. Alternatives to policies aiming for drastic reductions of total harvest include size limits and catch-and-release fishing (Cooke \& Schramm 2007,
Gwinn et al. 2015). Harvest scenarios employing minimum (500 mm) or maximum (700 mm) size limits led to similar increases in population growth rate in our model (Fig. 4a) but were unable to prevent the population from declining if harvest pressure remained unchanged beyond the limit. Combining minimum and maximum size limits, while still insufficient to stabilise the population completely in the presented projections, increased population growth rates substantially. Harvest slot limits have proven to be a valuable option to meet conservation targets while ensuring fisher satisfaction in other systems (by maintaining the presence of large, harvestable individuals in the population, Arlinghaus et al. 2010, Gwinn et al. 2015). Such limits may thus be worth considering for the Mjøsa/Gudbrandsdalslågen recreational fishery, especially in combination with policies reducing total harvest. However, just like catchand-release fishing, which is becoming increasingly more popular in our study system, the efficiency of harvest slot limits depends strongly on hooking mortality, and thorough study and evaluation are needed prior to implementation (Post et al. 2003, Cooke \& Schramm 2007).

\subsection{Role of river regulation}

The effects of stocking and harvest on the Hunder trout population are intricately linked to hydropower production in the river, and we investigated potential synergistic effects with 2 consequences of river regulation: compromised spawning and rearing habitat below the dam (represented by spawner mortality below the dam and recruitment penalties) and additional mortality of smolts and upriver spawners associated with passing the dam on the downriver migration. Increasing recruitment penalties below the dam resulted in lower predicted population sizes and growth rates and altered the relative importance of up- and downriver reproduction (Fig. 3; Fig. S1.4 in Supplement 1). It is thus likely that the efficiency of mitigation strategies reducing harvest, dam passage mortality, and/or below-dam background mortality also depended on the degree to which recruitment is compromised below the dam (Figs. S1.5-S1.8 in Supplement 1). When early survival was assumed to be independent of spawning location, population dynamics were more sensitive to mortality of eggs, juveniles, and spawners downriver of the dam. This is a direct consequence of highly fecund, large individuals being much more likely to spawn below the dam (Fig. S2.4 in Supplement 2; Nater et al. 2020b). Mitigation 
measures improving dam survival of upriver smolts and spawners thus had very little effect, while measures leading to substantial increases in survival of large downriver spawners were predicted to be fairly efficient (Fig. 5). When assuming compromised downriver recruitment due to river regulation, on the other hand, large individuals spawning below the dam lost a large portion of their reproductive output. Recruitment above the dam and the survival of smolts during the downriver migration $\left(S_{d a m}\right)$ thus became relatively more influential (Figs. 3). Consequently, population persistence in the absence of stocking was more likely when dam passage mortality of smolts and spawners was reduced on top of measures limiting harvest and spawner mortality below the dam (Figs. S1.7 \& S1.8 in Supplement 1). Ensuring persistence of the Hunder trout population at a size that allows for sustainable recreational fishing in the long-run is thus likely to require mitigation of not just harvest but also other human disturbances. The same conclusion has been reached previously for populations of Atlantic salmon (Gibson et al. 2009) and chinook salmon Oncorhynchus tshawytscha (Kareiva et al. 2000), and the entire salmonid assemblage in the Upper Great Lakes (Whelan \& Johnson 2004). In our study system, measures for mitigating negative impacts due to hydropower production could involve (1) increasing the number of large trout spawning upriver of the dam by improving the fish ladder, (2) reducing smolt and spawner dam mortality by installing safer downstream passages (Fjeldstad et al. 2018), and (3) restoring, protecting, and enhancing spawning habitat in the river (Trussart et al. 2002, Rubin et al. 2004).

\subsection{Model limitations and extensions}

Using a structured demographic model, we were able to explore potential effects of different management actions on population dynamics of the Hunder trout. However, it is important to be aware that our model makes some potentially restrictive assumptions, particularly about early life history. Depending on the degree to which assumptions differ from reality, the current model's predictions of population trajectories and effectiveness of management strategies may be more or less representative. The insights from our study could therefore be refined, improved, and made more valuable to management in practice by extending and building on the model presented here in several ways.

One central limitation of the model presented here is that it does not account for potential impacts of density-dependent feedbacks. Compensatory density dependence in early life, for example, is well documented in fish and may prevent population collapse through improved recruitment and juvenile survival at low population sizes (Rose et al. 2001, Lorenzen 2005). In the case of the Hunder trout, compensatory recruitment may contribute to protecting the population from extinction following termination of stocking, but is unlikely to prevent a substantial decrease of population size in general, and of abundance of ecologically and culturally important large fish in particular. This is indicated by our finding that very high values of both early and juvenile survival would be necessary to prevent population decline (Fig. S3.3 in Supplement 3) and supported by exploratory analyses including early life density feedbacks, which show that even if compensatory natural recruitment could fully compensate for termination of stocking in terms of total population size, the number of large, harvestable fish would still decrease substantially (see Supplement 5). Furthermore, such strong compensatory responses in recruitment seem unlikely in a system like ours in which spawning habitats are heavily impacted by river regulation, and evidence is accumulating from other populations of freshwater salmonids showing that compensatory density feedbacks may be unable to keep pace with strong extrinsic environmental stressors (e.g. Crozier et al. 2008, Bassar et al. 2016). Nonetheless, when it comes to developing explicit management strategies aimed at increasing natural recruitment, accounting for potential effects of compensatory density dependence will be central. The same applies to the opposite type of density feedbacks, i.e. depensatory density dependence or Allee effects, which have the potential to speed up extinction (Keith \& Hutchings 2012), particularly in combination with concurrent environmental change (Winter et al. 2020). In addition to affecting the early life of trout in the river, population density may further impact harvest dynamics and, by extension, the effectiveness of a variety of mitigation measures: fishers may change their effort and behaviour in response to fish population size, and this can impact the effects of changes in fishing regulations (e.g. Post et al. 2003). Accounting for density-dependent effects in both early life and harvest may thus improve our mechanistic understanding of this and similar systems and their responses to human activity, in particular at low population size. Drawing on recent meta-analyses of density dependence will be useful in this context (e.g. Foss-Grant et al. 2016, Thorson 2020), and we see appropriate extensions of the present model as a promising future direction. 
The main reasons why density feedbacks were not investigated in detail in this study were (1) lack of data to quantify processes in early life history and (2) absence of representative estimates of population size. Given the lack of individual-based data for much of the early life history, several vital rates in the model had to be derived from literature values for populations with similar life histories. While our general conclusions were robust to the choice of literature parameters (Supplement 3), efforts to collect population-specific data on egg, juvenile, and subadult mortality would greatly enhance the ability of our model to make robust quantitative predictions, and may further open up possibilities for assessing potential effects of early life density feedbacks. An alternative would be to formally account for uncertainty surrounding parameters derived from literature, for example by including probability distributions for these parameters instead of averages. A promising framework for doing so is the recently developed combination of IPMs with Bayesian integrated data analysis (Plard et al. 2019a). Besides allowing to account for uncertainty in literature-derived parameters, integrated frameworks also provide estimates of population size, which can be used to explicitly model density feedbacks (Plard et al. 2019b). Another key advantage of recasting our model in an integrated framework would be the possibility to quantify uncertainty in model predictions under different scenarios, which is highly relevant when it comes to comparing and deciding on management strategies (Williams et al. 2002).

Integrated modelling frameworks can also be used to model changes in genetic variation alongside demographic mechanisms (e.g. Pierson et al. 2015, Coulson et al. 2017, Willoughby \& Christie 2019). The biggest concern regarding stocking programmes and the main argument for their termination is the associated loss of genetic variation and the resulting decrease in the capacity of a population to adapt to environmental change (Laikre et al. 2010). Coupling a demographic model, such as the one presented here, with genetic analyses to quantify past and future impact of stocking on genetic variation of the Hunder trout would therefore be useful. Such analyses could further aid in developing strategies for enhancing stocking practices to minimise negative genetic and demographic impacts (Araki \& Schmid 2010) and for weighing different stocking practices against compensatory mitigation measures (Arlinghaus et al. 2002, Johnston et al. 2018, Janowitz-Koch et al. 2019). In a broader context, re-casting the model in a framework that also accounts for genetic changes would open the door to thorough studies of eco-evolutionary dynamics. Ultimately, this may allow quantifying genetic changes resulting not only from stocking, but potentially also from selection induced by harvesting (Heino et al. 2015), fish ladder passage (Haraldstad et al. 2020), and environmental changes as well as assessment of the impact of these changes on population persistence and efficiency of management strategies in a future under climate change.

\subsection{Towards sustainable management in a changing climate}

Developing sustainable management strategies for freshwater species in the Anthropocene requires not only considering the joint effects of stocking, hydropower production, and harvest, but doing so in the context of climate change. The most frequently studied climate change impacts on trout populations are those mediated by changes in stream flow and water temperature (Jonsson \& Jonsson 2009, Kovach et al. 2016). For the Hunder trout, previous studies indicated that neither average river/lake temperature nor river flow substantially affected growth (Nater et al. 2018). Mortality of spawners was only slightly influenced by river discharge, but was substantially lowered in years with fungal disease outbreaks (Nater et al. 2020b), which may become more prevalent as water temperatures continue to increase (Okamura \& Feist 2011). This highlights how changes in the abiotic environment can affect salmonid fishes through complex and interlinked pathways across different trophic levels (e.g. Kovach et al. 2016, Korman et al. 2021). Climate change also has impacts on freshwater ecosystems that extend beyond water temperature and flow, and towards both local-scale chemistry (Benson et al. 2012, Reid et al. 2019) and large-scale cryospheric processes (ice phenology, snowfall, glacier melt, etc., Woodward et al. 2010, Caldwell et al. 2020). Increasing frequency of extreme weather events (e.g. droughts, floods, cold spells) may further jeopardize hydropower infrastructure (Mikellidou et al. 2018), which may have devastating consequences for fish recruitment. Making reliable predictions, and developing sustainable management strategies, for freshwater species in a changing climate will therefore require coupling population models to climatic models at multiple scales (see, for example, Crozier et al. 2008) while also considering indirect impact through trophic interactions and, potentially, infrastructure functioning. 


\section{CONCLUSIONS}

We used an IPM structured by body size and life stage to study the dynamics of a population of brown trout exposed to multiple human impacts: long-term stocking with captive-bred individuals, intensive harvest, and river regulation. Our model projections indicated that current levels of exploitation are only possible due to the large-scale stocking programme. Termination of stocking is therefore likely to lead to a population decline and substantially lower numbers of harvestable fish, unless appropriate mitigation measures are implemented simultaneously. We explored potential relative impacts of different combinations of management strategies, highlighting that harvest slot limits, particularly in combination with efforts to restore spawning habitat impacted by the hydropower dam, have the potential to be effective, and thus warrant further investigation and consideration by management authorities. In general, a precautionary approach to management seems sensible and further studies are clearly needed. Such studies will hinge on both extended modelling frameworks and continued data collection, and should aim for a thorough consideration of the needs and constraints of different stakeholders while also taking into account emerging threats linked to climate change.

Data and code accessibility. Long-term individual-based data underlying the estimates used in this study are available on the Dryad Digital Repository (Nater et al. 2020a), and documented in the accompanying data paper (Moe et al. 2020). Code for building the IPM and running sensitivity and perturbation analyses is available on GitHub: https:// github.com/ChloeRN/HunderTroutIPM.

Acknowledgements. This work was supported by the Research Council of Norway (project SUSTAIN, 244647/E10). We thank Erik Friele (County Governor of Oppland) and Frank Hansen (Hunderfossen hatchery) for providing smolt release reports, and all participants of 2 stakeholder meetings for contributing to the discussions leading up to this paper. We also extend our thanks to 3 anonymous reviewers whose comments helped to improve the manuscript.

\section{LITERATURE CITED}

Aas $\varnothing$, Cucherousset J, Fleming IA, Wolter C and others (2018) Salmonid stocking in five North Atlantic jurisdictions: identifying drivers and barriers to policy change. Aquat Conserv 28:1451-1464

Aass P (1993) Stocking strategy for the rehabilitation of a regulated brown trout (Salmo trutta L.) river. Regul Rivers Res Manag 8:135-144

Aass P, Kraabøl M (1999) The exploitation of a migrating brown trout (Salmo trutta L.) population; change of fishing methods due to river regulation. River Res Appl 15:
211-219

Aass P, Nielsen PS, Brabrand Å (1989) Effects of river regulation on the structure of a fast-growing brown trout (Salmo trutta L.) population. Regul Rivers Res Manag 3: 255-266

Allendorf FW, Luikart GH, Aitken SN (2013) Conservation and the genetics of populations, $2^{\text {nd }}$ edn. Wiley-Blackwell, Chichester

Araki H, Schmid C (2010) Is hatchery stocking a help or harm? Evidence, limitations and future directions in ecological and genetic surveys. Aquaculture 308:S2-S11

* Arlinghaus R, Mehner T, Cowx IG (2002) Reconciling traditional inland fisheries management and sustainability in industrialized countries, with emphasis on Europe. Fish Fish 3:261-316

Arlinghaus R, Matsumura S, Dieckmann U (2010) The conservation and fishery benefits of protecting large pike (Esox lucius L.) by harvest regulations in recreational fishing. Biol Conserv 143:1444-1459

Arlinghaus R, Lorenzen K, Johnson BM, Cooke SJ, Cowx IG (2016) Management of freshwater fisheries: addressing habitat, people and fishes. In: Craig JF (ed) Freshwater fisheries ecology. John Wiley \& Sons, Chichester, p 557-579

*Bassar RD, Letcher BH, Nislow KH, Whiteley AR (2016) Changes in seasonal climate outpace compensatory density-dependence in eastern brook trout. Glob Change Biol 22:577-593

Benson BJ, Magnuson JJ, Jensen OP, Card VM and others (2012) Extreme events, trends, and variability in northern hemisphere lake-ice phenology (1855-2005). Clim Change 112:299-323

* Brown JJ, Limburg KE, Waldman JR, Stephenson K, Glenn EP, Juanes F, Jordaan A (2013) Fish and hydropower on the US Atlantic coast: failed fisheries policies from halfway technologies. Conserv Lett 6:280-286

Caldwell TJ, Chandra S, Feher K, Simmons JB, Hogan Z (2020) Ecosystem response to earlier ice break-up date: climate-driven changes to water temperature, lake-habitat-specific production, and trout habitat and resource use. Glob Change Biol 26:5475-5491

Caswell H (2001) Matrix population models: construction, analysis, and interpretation. Sinauer Associates, Sunderland, MA

KCooke SJ, Schramm HL (2007) Catch-and-release science and its application to conservation and management of recreational fisheries. Fish Manag Ecol 14:73-79

* Coulson T, Kendall BE, Barthold J, Plard F, Schindler S, Ozgul A, Gaillard JM (2017) Modeling adaptive and nonadaptive responses of populations to environmental change. Am Nat 190:313-336

Crozier LG, Zabel RW, Hamlet AF (2008) Predicting differential effects of climate change at the population level with life-cycle models of spring chinook salmon. Glob Change Biol 14:236-249

* Dudgeon D, Arthington AH, Gessner MO, Kawabata ZI and others (2006) Freshwater biodiversity: importance, threats, status and conservation challenges. Biol Rev Camb Philos Soc 81:163-182

Ellner SP, Rees M (2006) Integral projection models for species with complex demography. Am Nat 167:410-428

* Ergon T, Borgan Ø, Nater CR, Vindenes Y (2018) The utility of mortality hazard rates in population analyses. Methods Ecol Evol 9:2046-2056

Festa-Bianchet M, Mysterud A (2018) Hunting and evo- 
lution: theory, evidence, and unknowns. J Mammal 99: 1281-1292

Fjeldstad HP, Pulg U, Forseth T (2018) Safe two-way migration for salmonids and eel past hydropower structures in Europe: a review and recommendations for best-practice solutions. Mar Freshw Res 69:1834-1847

Foss-Grant AP, Zipkin EF, Thorson JT, Jensen OP, Fagan WF (2016) Hierarchical analysis of taxonomic variation in intraspecific competition across fish species. Ecology 97 : 1724-1734

Gibson AJF, Jones RA, Bowlby HD (2009) Equilibrium analyses of a population's response to recovery activities: a case study with Atlantic salmon. N Am J Fish Manag 29:958-974

* Gwinn DC, Allen MS, Johnston FD, Brown P, Todd CR, Arlinghaus R (2015) Rethinking length-based fisheries regulations: the value of protecting old and large fish with harvest slots. Fish Fish 16:259-281

Haraldstad T, Höglund E, Kroglund F, Olsen EM, Hawley KL, Haugen TO (2020) Anthropogenic and natural sizerelated selection act in concert during brown trout (Salmo trutta) smolt river descent. Hydrobiologia https:// doi.org/10.1007/s10750-020-04329-4

He F, Zarfl C, Bremerich V, David JNW and others (2019) The global decline of freshwater megafauna. Glob Change Biol 25:3883-3892

*Heino M, Diaz Pauli B, Dieckmann U (2015) Fisheriesinduced evolution. Annu Rev Ecol Evol Syst 46:461-480

Huitfeldt-Kaas H (1916) Mjøsens fisker og fiskeries. K Norske Vidensk Selskaps Skr 2:1-257

Hutchings JA, Kuparinen A (2020) Implications of fisheriesinduced evolution for population recovery: refocusing the science and refining its communication. Fish Fish 21: 453-464

*Hutchings JA, Reynolds JD (2004) Marine fish population collapses: consequences for recovery and extinction risk. Bioscience 54:297-309

Janowitz-Koch I, Rabe C, Kinzer R, Nelson D, Hess MA, Narum SR (2019) Long-term evaluation of fitness and demographic effects of a chinook salmon supplementation program. Evol Appl 12:456-469

* Johnston FD, Allen MS, Beardmore B, Riepe C, Pagel T, Hühn D, Arlinghaus R (2018) How ecological processes shape the outcomes of stock enhancement and harvest regulations in recreational fisheries. Ecol Appl 28: 2033-2054

Jonsson B, Jonsson N (2009) Migratory timing, marine survival and growth of anadromous brown trout Salmo trutta in the River Imsa, Norway. J Fish Biol 74:621-638

Jørgensen C, Ernande B, Fiksen $\varnothing$ (2009) Size-selective fishing gear and life history evolution in the Northeast Arctic cod. Evol Appl 2:356-370

Kareiva P, Marvier M, McClure M (2000) Recovery and management options for spring/summer chinook salmon in the Columbia River Basin. Science 290:977-979

Keith DM, Hutchings JA (2012) Population dynamics of marine fishes at low abundance. Can J Fish Aquat Sci 69: 1150-1163

Korman J, Yard MD, Dzul MC, Yackulic CB, Dodrill MJ, Deemer BR, Kennedy TA (2021) Changes in prey, turbidity, and competition reduce somatic growth and cause the collapse of a fish population. Ecol Monogr 91:e01427

Kovach RP, Muhlfeld CC, Al-Chokhachy R, Dunham JB, Letcher BH, Kershner JL (2016) Impacts of climatic variation on trout: a global synthesis and path forward. Rev
Fish Biol Fish 26:135-151

Kraabøl M (2006) Gytebiologi hos Hunderørret i Gudbrandsdalslågen nedenfor Hunderfossen kraftverk. NINA rapport 217. NINA, Trondheim

Kuparinen A, Hutchings JA (2012) Consequences of fisheries-induced evolution for population productivity and recovery potential. Proc R Soc B Biol Sci 279: 2571-2579

* Laikre L, Schwartz MK, Waples RS, Ryman N, GEM Working Group (2010) Compromising genetic diversity in the wild: unmonitored large-scale release of plants and animals. Trends Ecol Evol 25:520-529

Lorenzen K (2005) Population dynamics and potential of fisheries stock enhancement: practical theory for assessment and policy analysis. Philos Trans R Soc B 360:171-189

McGinnity P, Jennings E, DeEyto E, Allott N and others (2009) Impact of naturally spawning captive-bred Atlantic salmon on wild populations: depressed recruitment and increased risk of climate-mediated extinction. Proc R Soc B 276:3601-3610

*Mikellidou CV, Shakou LM, Boustras G, Dimopoulos C (2018) Energy critical infrastructures at risk from climate change: a state of the art review. Saf Sci 110:110-120

Moe SJ, Nater CR, Rustadbakken A, Vøllestad LA and others (2020) Long-term mark-recapture and growth data for large-sized migratory brown trout (Salmo trutta) from Lake Mjøsa, Norway. Biodivers Data J 8:e52157

Museth J, Dervo B, Brabrand A, Heggenes J, Karlsson S, Kraabøl M (2018) Storørret i Norge. Definisjon, status, påvirkningsfaktorer og kunnskapsbehov. NINA rapport 1498. NINA, Trondheim, Norway.

*Naish KA, Taylor JE III, Levin PS, Quinn TP, Winton JR, Huppert D, Hilborn R (2007) An evaluation of the effects of conservation and fishery enhancement hatcheries on wild populations of salmon. Adv Mar Biol 53: 61-194

Nater CR, Rustadbakken A, Ergon T, Langangen Ø and others (2018) Individual heterogeneity and early life conditions shape growth in a freshwater top predator. Ecology 99:1011-1017

N Nater CR, Moe SJ, Rustadbakken A, Vøllestad LA, Lund E, Qvenild T, Hegge O, Aass P (2020a) Data from: Long-term mark-recapture and growth data for largesized migratory brown trout (Salmo trutta) from Lake Mjøsa, Norway, v3. Dryad, Dataset doi:10.5061/dryad. $9 \mathrm{cnp} 5 \mathrm{hqf} 4$

Nater CR, Vindenes Y, Aass P, Cole D and others (2020b) Size- and stage-dependence in cause-specific mortality of migratory brown trout. J Anim Ecol 89:2122-2133

* Ohlberger J, Thackeray SJ, Winfield IJ, Maberly SC, Vøllestad LA (2014) When phenology matters: age-size truncation alters population response to trophic mismatch. Proc R Soc B 281:20140938

Ohlberger J, Schindler DE, Brown RJ, Harding JM and others (2020) The reproductive value of large females: consequences of shifts in demographic structure for population reproductive potential in chinook salmon. Can J Fish Aquat Sci 77:1292-1301

* Okamura B, Feist SW (2011) Emerging diseases in freshwater systems. Freshw Biol 56:627-637

* Paquet PJ, Flagg T, Appleby A, Barr J and others (2011) Hatcheries, conservation, and sustainable fisheriesachieving multiple goals: results of the Hatchery Scientific Review Group's Columbia River basin review. Fisheries 36:547-561 
Pierson JC, Beissinger SR, Bragg JG, Coates DJ and others (2015) Incorporating evolutionary processes into population viability models. Conserv Biol 29:755-764

Plard F, Turek D, Grüebler MU, Schaub M (2019a) IPM²: toward better understanding and forecasting of population dynamics. Ecol Monogr 89:e01364

Plard F, Fay R, Kéry M, Cohas A, Schaub M (2019b) Integrated population models: powerful methods to embed individual processes in population dynamics models. Ecology 100:e02715

Post JR, Mushens C, Paul A, Sullivan M (2003) Assessment of alternative harvest regulations for sustaining recreational fisheries: model development and application to bull trout. N Am J Fish Manag 23:22-34

Reid AJ, Carlson AK, Creed IF, Eliason EJ and others (2019) Emerging threats and persistent conservation challenges for freshwater biodiversity. Biol Rev Camb Philos Soc 94: 849-873

Reynolds JD, Mace GM, Redford KH, Robinson JG (2001) Conservation of exploited species, Vol 6. Cambridge University Press, Cambridge

Rogers MW, Allen MS, Brown P, Hunt T, Fulton W, Ingram BA (2010) A simulation model to explore the relative value of stock enhancement versus harvest regulations for fishery sustainability. Ecol Model 221:919-926

Rose KA, Cowan JH, Winemiller KO, Myers RA, Hilborn R (2001) Compensatory density dependence in fish populations: importance, controversy, understanding and prognosis. Fish Fish 2:293-327

Rubin JF, Glimsäter C, Jarvi T (2004) Characteristics and rehabilitation of the spawning habitats of the sea trout,

Editorial responsibility: Nils Bunnefeld,

Stirling, UK

Reviewed by: 3 anonymous referees
Salmo trutta, in Gotland (Sweden). Fish Manag Ecol 11: 15-22

Stearns SC (1992) The evolution of life histories. Oxford University Press, London

Thorson JT (2020) Predicting recruitment density dependence and intrinsic growth rate for all fishes worldwide using a data-integrated life-history model. Fish Fish 21: $237-251$

* Trussart S, Messier D, Roquet V, Aki S (2002) Hydropower projects: a review of most effective mitigation measures. Energy Policy 30:1251-1259

Whelan GE, Johnson JE (2004) Successes and failures of large-scale ecosystem manipulation using hatchery production: the upper Great Lakes experience. Am Fish Soc Symp 44:3-32

Williams BK, Nichols JD, Conroy MJ (2002) Analysis and management of animal populations. Academic Press, San Diego, CA

Willoughby JR, Christie MR (2019) Long-term demographic and genetic effects of releasing captive-born individuals into the wild. Conserv Biol 33:377-388

WWinter AM, Richter A, Eikeset AM (2020) Implications of Allee effects for fisheries management in a changing climate: evidence from Atlantic cod. Ecol Appl 30: e01994

Woodward G, Perkins DM, Brown LE (2010) Climate change and freshwater ecosystems: impacts across multiple levels of organization. Philos Trans R Soc B 365:2093-2106

*Woolway RI, Maberly SC (2020) Climate velocity in inland standing waters. Nat Clim Change 10:1124-1129

Submitted: July 29, 2020

Accepted: February 22, 2021

Proofs received from author(s): May 19, 2021 